\title{
As crises silenciadas pela modernidade e pelas tecnologias da cultura da virtualidade real 1
}

The silenced crisis of modernity and culture technologies of real virtuality

MARIA ChristianNI COUTINHO MARÇAL

Doutoranda e professora na Universidade Federal de Pernambuco - UFPE. <chrismarcal@hotmail.com>

Sérgio CarvalHo Benício de Mello

Doutor pela City University London - Cass Business School. Professor da UFPE. <sergio.benicio@pesquisador.cnpq.br>

MARIA IRAÊ DE SOUZA CORRÊA

Doutoranda na UFPE. Professora na Universidade Rural Federal de Pernambuco. <mariairae@hotmail.com>

\section{RESUMO}

Esse artigo visa refletir as crises presentes em nossa cultura contemporânea impregnada pela modernidade e pelos meios de comunicação e digitalização que daquela emanam. A primeira crise que refletimos foi a da quebra da promessa da modernidade que se embasava em progresso, democracia e emancipação do homem. A outra crise a qual nos referimos se dá devido à interferência que as tecnologias promovem no âmbito da percepção humana gerando uma espécie de "cegamento" que objetiva, reifica e unifica as representações dos fenômenos cotidianos interpelando e desestabilizando os referenciais éticos e estéticos que dão sentido às experiências e que constroem a subjetividade humana, as relações sociais e a vida política, nos fazendo repensar o que vem a ser considerado o real.

Palavras-chave: Modernidade; Cultura virtual; Real.

\section{ABSTRACT}

This article aims to reflect the present crises in our contemporary culture permeated by modernity and by the media and digital technologies that emanate from that. The first crisis reflected was the broken promise of modernity that underlay in progress, democracy and human emancipation. The other crisis to which we refer is due to the technology interference in the context of human perception creating a kind of "blindness" that objective, reified and unifies the representations of everyday phenomena interpellating and destabilizing the ethical and aesthetic references that give meaning to the experiences and that build human subjectivity, social relations and political life, making us rethink what is to be considered real.

KEYwORDs: Modernity; Virtual culture; Real. 


\section{Apontamentos sobre tecnologia, virtualidade e realidade}

onipresença das tecnologias da informação e comunicação como mediadora das Inossas experiências cotidianas produz um efeito de real que nos conduz a uma forma quase exclusiva de informar, de comunicar, de apreender a realidade, de mover, de comprar e de vender; alterando as bases nas quais os significados sociais são construídos. Sendo assim, a tecnologia se insere, no contexto do mundo contemporâneo, como um elemento-chave, não só mediando as pessoas e o mundo, mas, como um instrumento que media hoje, de modo mais intenso e acelerado, a transformação da sociedade em mercado, o que acarreta em alguns problemas, pois a lógica deste é outra, diferente da lógica da sociedade enquanto elemento norteador e propagador de sentido, de valores e de condutas comunitárias (Martín-Barbero, 2003).

Como extensões do nosso corpo, as tecnologias nos tornam cada vez mais dependentes para estabelecer relações, nos fazendo questionar acerca do que vem a ser esse real mediado pelas novas tecnologias da informação e comunicação. Pois, pouco a pouco, as tecnologias se instalam de forma generalizada em nossas vidas modificando o uso dos nossos sentidos, nos conduzindo a novas realidades e novas maneiras de ser humano.

Nesse ponto (res)surge a ideia de virtual e as questões relativas à virtualidade como caminhos para a compreensão da experiência contemporânea. Podemos considerar que o virtual acompanha os processos da humanidade como uma dimensão constitutiva do ser humano e suas relações em sociedade (Deleuze; Guattari, 1993). Entendendo essa importância, alguns pensadores (e.g., Paul Virilio, Jean Baudrillard, Sherry Turkle, André Lemos, Francisco Rüdiger, entre outros) contemporâneos têm problematizado a tecnocultura, marcada pela onipresença das imagens das telas de computadores como mediadoras das relações sociais e apontando os possíveis impactos na subjetividade humana. 
Dessa forma, a discussão acerca do fenômeno da virtualidade e da natureza do virtual foi resgatada, no âmbito da filosofia, por Deleuze e Guattari (1993) para quem o conceito de virtual se refere à dimensão do real enquanto potência que se atualiza circunstancialmente em nossa experiência cotidiana, em conjunto com as condições com as quais se confronta. $\mathrm{O}$ virtual seria então uma dimensão do real e não seu oposto, "uma dimensão complexa, caótica e dinâmica que convoca atualizações inventivas e imprevisíveis da ordem do acontecimento" (Brasil, 2008).

Deste modo, o virtual deve ser entendido como uma parte do objeto real - como se o objeto tivesse uma de suas partes no virtual e aí mergulhasse como numa dimensão objetiva (Deleuze; Guattari, 1993). Os autores consideram que o real encontra-se imerso em uma névoa de virtualidades, em sua potência e complexidade, onde se escapa ao controle dos esquemas de representação, mapas cognitivos e códigos sociais que estruturam a vida social. Trata-se, portanto do espaço da arte, da invenção e da subversão que, a despeito das restrições institucionais, compõem nossa rotina, trazendo a abertura para as imprevisibilidades. Outro aspecto a ser considerado quando se trata da virtualidade, é a desterritorialização do virtual, sua não-presença, que introduz uma ruptura na relação espaço-tempo que organiza as relações sociais. De que modo, então, a profusão das telas no nosso cotidiano, expressão material da mediação tecnológica, nos encaminha para um fechamento do real, transformando nossas percepções e nos levando a um cegamento do olhar?

A crítica desapareceu pouco a pouco e deslizamos inconscientemente da pura tecnologia para o dogmatismo da tecnocultura. Cultura da técnica onde há simulações de experiências "reais" nas quais os indivíduos têm consciência do momento experienciado e a presença maciça de simulacros que são as realidades representadas e consentidas pelas imagens que ela prolifera. Podemos compreendê-la, também, como a cultura do virtual (Lévy, 1996; Baudrillard, 1991, 1999), da virtualidade real (Castells, 
1999, 2003), da proliferação de imagens, de sons, da velocidade, da efemeridade, da cibercultura, do ciberpunk, dos videogames e da primazia do consumo de imagens (Marçal, Mello e Corrêa, 2007).

Embora as polêmicas em torno na natureza do real tenham originado diversas linhas teóricas ao longo do último século, podemos considerar que o entendimento dominante acerca daquilo que é real, encontra-se fortemente influenciado pela ciência moderna, que estabeleceu os princípios que ainda norteiam das ideias do homem atual, conforme exploraremos na próxima seção deste trabalho.

\section{As crises relacionadas à modernidade, seus pressupostos e à ciência}

O movimento da modernidade se estabeleceu como o contraponto das sociedades tradicionais e impunha, através da "liberação" do Homem, a destruição de laços, sentimentos e costumes atrelados ao tradicionalismo. $\mathrm{O}$ movimento privilegia o conhecimento científico, negligencia o senso-comum, e suprime os princípios das essências de suas entidades artificiais que são o self e as culturas, em benefício do conhecimento científico, dos mecanismos biopsicológicos e das regras impessoais "não escritas" de troca dos bens, das palavras e do comportamento (Touraine, 1994).

Os pressupostos modernistas, baseados nos ideais iluministas, são que o progresso é o caminho para a sociedade adquirir abundância, liberdade e felicidade, e tem como pano de fundo o desenvolvimento da cultura de consumo; e como elemento norteador a razão que promete "autonomia" ao Homem (Touraine, 2004; Slater, 2002; Virilio, 1996).

A modernidade, identificada com o triunfo da razão, é a última forma tomada pela investigação tradicional do Uno, do Ser. Nela, então, há a visão de que o corpo é unidade pré-social e biológica sobre a qual um self e uma sociedade se constituiriam; o que acarretou em produzir diferenças e discriminações étnicas em um momento 
da história e outros tipos de discriminações. Como afirma Plastino (2001, p. 26) a modernidade "pretendeu fundamentar a pertinência de sua concepção ontológica na eficiência que reduz a totalidade do real ao determinado e faz da ciência moderna o modelo de uma racionalidade exclusiva, progressivamente estendida do estudo da natureza, para o estudo da sociedade e do homem".

O paradigma do conhecimento moderno está apoiado na observação sistemática e rigorosa dos fenômenos naturais, foram fortemente influenciados pela matemática, que forneceu o instrumento de análise e o modelo de representação e organização do real. Assim, nessa perspectiva, conhecer significa quantificar, as qualidades intrínsecas dos objetos são substituídas por quantidades, a complexidade do real é ignorada em benefício da simplicidade das leis determinísticas, predominando a ideia de real associada a real-físico formado pela matéria (Plastino, 2001, p. 25).

Entretanto, uma realidade paradoxal nos é apresentada, pois o projeto iluminista de modernidade e a modernidade concreta, advinda das ruas, fábricas e das novas relações de trabalho não se apresentam como pólos conciliáveis. Pois, a modernidade acumulou em nós, seres [pós] modernos uma pletora de danos específicos, que incluem problemas visuais, sociais, afetivos, intelectuais, sexuais, que se sedimentou em cada inovação que nos foi apresentada (Marçal; Mello e Guerra, 2006).

A modernidade é composta por uma linguagem pluralizada (Berger; Luckman, 2004) e complexa na qual a leitura moderna não dá conta de interpretar. Assim, do mundo "verdadeiro" e quantificado da modernidade só restam ruínas, mas sobre estas ruínas se erguem novas tábuas de valores onde a [pós] modernidade é terra fértil para a proliferação do efêmero, da volatilidade, da descartabilidade e da estetização da vida cotidiana. Dessa forma, podemos compreender a crise da modernidade como sendo o esgotamento do movimento dos iluministas em sua fase inicial que prometia a liberdade ao homem da ex-sociedade tradicional. Um dos aspectos centrais desta 
crise é a perda de sentido de uma cultura que se sentia enclausurada na técnica e na razão instrumental não articulando espaço para a questão da subjetividade humana e consequentemente para a humanização.

\section{O ruir da ciência moderna: a complexidade da relação sujeito-objeto e o real}

Observa-se que a partir de meados do século passado, ocorreu uma reviravolta nas concepções do sujeito, da relação sujeito-objeto e do conhecimento. Os próprios avanços das ciências naturais ruíram os pilares da ciência moderna apontando para a impossibilidade de uma realidade estável, independente do observador e que se deixa representar pela mente racional.

Um dos reconhecidos abalos foi a emergência da psicanálise que trouxe uma ruptura radical com os pressupostos deterministas e simplificadores do paradigma moderno hegemônico, ao conceber o homem como ser guiado por uma afetividade, anterior à razão - que não pode ser considerada sua exclusiva fonte de saber e apreensão do real.

Plastino (2001) afirma que a psicanálise emerge como um pensamento complexo, cuja validade é retirada da intersubjetividade na qual é produzido configurando-se como um saber capaz de apreender a singularidade do homem e de suas relações com a natureza. "Na concepção do que é possível elaborar a partir das ciências e saberes contemporâneos, o real estático e eterno suposto pelo paradigma moderno é substituído por uma totalidade aberta, em perpétuo devir, incluindo nesse processo nossa própria participação" (Plastino, 2001, p. 36).

As investigações acerca do psiquismo humano empreendidas principalmente por Freud e Lacan, trouxeram luz sobre elementos estruturantes do inconsciente, que participam da formação psíquica, o imaginário, o simbólico e o Real, saberes 
que se estruturam em uma linguagem, que não é nem individual, nem coletiva, mas opera no espaço entredois (Nasio, 1993). Este conhecimento psicanalítico pode ser considerado fundamental à medida que atua na elucidação do modo como o inconsciente participa não apenas dos processos do próprio psiquismo, mas também do real externo, conforme afirma Plastino (2001, p. 39): “A compreensão das possibilidades de construção de relações alternativas entre o homem e o real de novas formas de relacionamento humano e social é hoje muito mais rica e complexa do que no alvorecer da modernidade.

Assim, a problemática do real na sociedade contemporânea, as questões referentes à natureza do real e aquilo que estamos dispostos a considerar real devem partir da ideia de um real complexo, que supera as dicotomias entre "mundo das coisas" e "mundo das ideias", na busca pelo entendimento do modo como ocorrem as relações entre as diferentes dimensões que participam da constituição do real, que não são inteligíveis quando nos reduzimos aos processos racionais.

Neste sentido, Zizek (1997) aborda a força constitutiva da fantasia e sua centralidade para o entendimento do sujeito desejante, uma vez que, segundo o autor, a fantasia fornece coordenadas, ou literalmente "ensina-os como desejar". A fantasia, então, situa-se como um agente mediador entre a estrutura simbólica formal e a positividade de objetos que nós encontramos na realidade - ou seja, ela fornece um esquema, no qual, certos objetos positivos na realidade podem funcionar como objetos de desejo, preenchendo o espaço vazio aberto pela estrutura simbólica formal.

Diante da constância com que nossas experiências sociais envolvem simulações, poderíamos nos deparar com uma situação na qual consideraríamos o que chamamos de vida real como se fosse apenas mais uma janela de um hipertexto, ou o seu oposto, a atitude do senso comum de que é possível uma realidade fora do universo virtual. Para Zizek (1997) ambas as posições envolvem armadilhas, uma vez que as inovações 
da biotecnologia, da genética, da nanotecnologia, para citar as mais conhecidas, minam a diferença entre natural e artificial, entre o homem e a máquina.

Assim, como aponta o supracitado autor, a nossa experiência hermenêutica cotidiana é minada com esta quebra de fronteiras, com a interconexão de opostos na experiência diária. Essa "perda da realidade" ocorre não somente em relação às experiências virtuais geradas pelas telas do computador, mas, em um nível mais primário, já nas imagens do hiper-realismo, presentes na mídia, nas quais estamos imersos e com as quais construímos nossa ideia de realidade.

\section{A virtualidade e a implosão do social}

Na cultura da virtualidade real, substituímos a interação face a face pela interface dos computadores, uma nova superfície que anula a separação clássica de posição, de instante ou de objeto, e também a tradicional divisão do espaço em dimensões físicas, em benefício de uma configuração instantânea, ou quase, em que o observador e o observado são bruscamente confundidos e ligados.

Nessa realidade advinda da era da comunicação digitalizada, na qual a internet é o seu maior ícone, o que for mais presente, o que aconteceu neste momento ganha maior destaque. O tempo de duração é substituído pelo tempo real, e este é o tempo de exposição na tela (Virilio, 1998). O tempo se superpõe ao espaço, na relação ontológica clássica, e a velocidade ganha destaque. A questão da realidade e da própria definição do real e do figurado passa a ser a do trajeto, a do intervalo luz.

Essa realidade desmaterializa e desterritorializa os sujeitos, que gera a inércia dos seus sentidos e dos movimentos e que impactam em sua subjetividade esvaziando seus quadros de significação ontológicos restringindo seu campo de liberdade de ação.

Refletindo sobre o modo como a virtualidade se apresenta na sociedade contemporânea, Castells (1999) considera que atualmente temos como específico um 
sistema de comunicação organizado pela integração eletrônica dos diversos modos de comunicação que gera a cultura da virtualidade real que, segundo o autor:

[...] é um sistema em que a própria realidade (ou seja, a experiência simbólica/material das pessoas) é inteiramente captada, totalmente imersa em uma composição de imagens virtuais no mundo do faz-de-conta, no qual as aparências não apenas se encontram na tela comunicadora da experiência, mas se transformam na experiência.

(Castells, 1999, p. 459)

Turkle, em entrevista a Casalegno (1999), sugere que, ao invés de se falar em real e virtual, fale-se em virtual e resto da vida, justificando que as pessoas gastam tempo e energia emocional no virtual, então, por que falar do "material" como se fosse o único real. A vida online abre o espaço para a exploração, para a aventura, na medida em que as coisas se fecham e o espaço se reduz, o ciberespaço propõe alguma coisa da ordem do espaço-jogo: uma chance de experimentação inexistente no resto da vida.

Deste modo, para a supracitada autora, vida online e a vida off-line podem estar tão profundamente interligadas que suas fronteiras estarão sempre ameaçadas. Diante desta erosão de fronteiras, Zizek (1997, p. 133) questiona: “Como a computação afeta o horizonte hermenêutico da nossa experiência?". Diante desta condição e dos desdobramentos que se apresentam, os possíveis impactos das transformações em curso têm sidos debatidos no âmbito das ciências humanas.

Pierre Levy tem sido considerado um dos representantes de uma aproximação otimista em relações a esses impactos. Levy (1996) considera que estamos diante 
de possibilidades que apontam, de um lado, para a crescente espetacularização e massificação impulsionadas pelo capitalismo globalizado, mas por outro lado também podemos considerar:

[...] as tendências mais positivas da evolução em curso e criamos um projeto de civilização centrado sobre os coletivos inteligentes: recriação do vínculo social mediante trocas de saber, reconhecimento, escuta e valorização das singularidades, democracia mais direta, mais participativa, enriquecimento das vidas individuais, invenção de formas novas de cooperação aberta para resolver os terríveis problemas que a humanidade deve enfrentar, disposição das infra-estruturas informáticas e culturais da inteligência coletiva.

(Levy, 1996, p. 118)

De um ponto de vista crítico, Baudrillard (1999, p. 26) aponta os limites do que ele considera um "otimismo tecnológico delirante". A questão relaciona-se a uma perspectiva na qual, na sociedade contemporânea, a dimensão virtual encontra-se esvaziada em sua condição de abertura do real, deixando de ser potência, uma vez que seu espaço encontra-se totalmente preenchido pelas telas, como um produto de exteriorização de construções mentais em espaços de interação cibernéticos.

A tela do computador abruptamente se tornou a praça da cidade e a estrada de todas as mídias de massa. É através dela que as nossas percepções são alteradas não importando se é através de um computador, uma televisão ou um videogame, é o meio que vai nos transportar para as novas perspectivas ontológicas. A tela "aparece" 
como a última parede da arquitetura do mundo matéria que propicia a automação da percepção, a visão sintética, síntese de um espaço crítico que se torna acrítico (Virilio, 1993).

Na verdade, é na tela que se produz a visão sem olhar, a visão como uma reprodução de um intenso cegamento, que se torna uma nova e última forma de industrialização: a industrialização do não-olhar (Virilio, 1998). “Queira-se ou não, toda relação interpessoal, toda comunicação, toda atividade cognitiva nos envolve inconscientemente nessa violência não sancionada de uma comoção ótica que se tornou global" (Virilio, 1999, p. 73) através das comunicações digitalizadas.

A tela é a representação da passagem do material para algo que imaterial, é a perspectiva, o ponto de partida e de chegada do tempo real, o nosso grande interlocutor, que nos encaminha para o mundo das imagens de síntese. A superação das imagens digitais em detrimento das imagens a "olho nu" (Virilio, 1996) gera um fenômeno de pura representação, um relativismo que estará sempre presente na aparência dos acontecimentos, nas coisas presentes, na própria interpretação subjetiva necessária ao reconhecimento das formas, dos objetos e das cenas das quais somos testemunhas (Virilio, 1994).

O resultado político é uma democracia automática exercida por meio de uma deliberação compensada, uma democracia reflexa sem reflexão coletiva que se limita a reproduzir pesquisas de opinião que influencia as pessoas. Assim, o mundo se transforma em um "grande objeto", como uma ilusão de ótica de fé perceptual que nos introduz para a realidade e nós somos parte desse objeto (Virilio, 1996).

Neste sentido, a inteligência eletrônica e os avanços nos estudos do campo eletromagnético se mostram como uma das maiores armas contemporâneas, pois, "uma questão crucial aparece nesse instante preciso da história: pode alguém democratizar ubiqüidade, instantaneidade, onisciência e onipresença que precisamente privilegia o 
divino, ou em outras palavras, autocracia?"(Virilio, 1998, p. 181). Ou seja, é o equivalente à criação de seqüências de automatismos, procedimentos industriais e científicos reacionários dos quais se faz ausente qualquer escolha política (Virilio, 1996).

Baudrillard (1999) entende que a extensão do virtual impulsiona um esvaziamento do real e o fim da comunicação, o que leva a implosão do social:

[...] a extensão incondicional do virtual [...] determina a desertificação sem precedentes do espaço real e de tudo o que nos cerca. Há um precedente com o social: o patamar da massa social crítica já está amplamente ultrapassado com a expansão populacional, das redes de controle, de socialização, de comunicação, de interatividade, com a extrapolação do social total - provocando desde agora a implosão da esfera real do social e de seu conceito. Quando tudo é social, súbito nada mais o é.

(Baudrillard, 1999, p. 24-25)

Ao se privar da substancialidade da matéria e dos seus artefatos embebidos nos contextos culturais, ao encurtar o tempo de duração da experiência, aniquila-se a possibilidade de resgate da consciência e da agência humana, fatores fundamentais para exercício da política e cidadania pressupostos para a vida em sociedade.

Essa é a era da transcendência tecnológica, parece que Deus está sendo substituído pela tecnologia no nosso pensamento metafísico, pois somos reféns dos seus feitos para poder ser incluído no mundo digitalizado, unificado e unilateral que nos é apresentado. O que se traduz em uma visão bastante determinística. Frente ao exposto, podemos afirmar que a crise que vivemos em nossa contemporaneidade não é mais a crise da 
modernidade per se, mas a própria crise do discurso da sua narrativa que constrói um real visivelmente oferecido a todos. Ou seja, sua capacidade universalmente reconhecida de dizer, de descrever e inscrever o real.

\section{Considerações finais}

A nossa sociedade está imersa em um processo de construção da realidade baseada na cultura das tecnologias da comunicação e digitalização, que delineia como os indivíduos têm suas percepções aprisionadas pelas idéias que servem a um conjunto específico de interesses dos detentores do capital. Podemos observar o potencial de acidentes que as tecnologias geram e que não estão sendo refletidos pelos seus usuários. Um dos mais graves é a exclusão do mundo social para aqueles que não conseguem fazer uso dela e que vocifera uma visão de mundo essencialista onde todas as coisas do mundo parecem ter sido colonizadas por ela nos levando a uma cultura que enfatiza a racionalidade técnica.

Sendo assim, para pensar em uma ontologia social, que nos guie na compreensão dos fenômenos da sociedade contemporânea, não podemos deixar de levar em conta as forças que nos imergem na tecnocultura. Que forças são essas? Posso realmente me conectar ou me desconectar da realidade com um clic? A visão do ciberespaço de abertura para um futuro de possibilidades infinitas de mudança sem limites, e assim por diante, é exatamente seu oposto: uma imposição desconhecida do fechamento radical.

De que modo, no ciberespaço, realizamos uma espécie de fechamento do real? Ou, como questiona Baudrillard (1991): há no ciberespaço a possibilidade de descoberta, ou o que existe é a simulação de liberdade, onde interagimos com fragmentação, convencionalismos, sites estabelecidos e códigos instituídos? No ciberespaço, onde há a suspensão das distâncias, induz-se uma claustrofobia indesejada onde o excesso de escolha é experienciado como a impossibilidade de escolher. 
Passamos, então, a refletir acerca da natureza do humano, a partir do momento em que, como afirmam Virilio (1996) e Zizek (1997), a colonização do espaço de fora se reverte em uma endocolonização, a colonização tecnológica do próprio corpo. Não apenas com a possibilidade da implantação de próteses computadorizadas nosso organismo, mas também na constituição do sujeito-descarrilado, ao qual falta o suporte instintivo para a coordenação entre o ritmo natural do corpo e seu ambiente, povoando-o de excessos.

Deste modo, nos vemos diante de uma condição na qual a tecnologia assume o lugar de uma "segunda natureza" humana, uma condição na qual a humanidade a produz ao mesmo tempo em que por ela é produzida (Raleiras, 2007). Assim, em uma possibilidade de futuro, o ser humano vai gradualmente perder suas bases com o mundo concreto da vida - isso quer dizer que o grupo de coordenadas que determina a auto-experiência (a base que separa o que está dentro do que está fora, a relação direta com o próprio corpo, etc.) - terá suas fronteiras transpostas; entretanto, outras bases estão sendo criadas necessitando de melhores esclarecimentos em torno dos seus impactos e influências.

\section{REFERÊNCIAS}

BAUDRILLARD, Jean. Simulacros e Simulação. Lisboa: Relógio D’Água Editores, 1991. Tela Total - Mito-Ironias da Era do Virtual e da Imagem. Porto Alegre, 1999.

BERGER, Peter L.; LUCKMANN, Thomas., Modernidade, pluralismo e crise de sentido: A orientação do homem moderno. Petrópolis: Vozes, 2004.

BRASIL, André. O Virtual Desbotado das Webcams. Disponível em: <http://bocc.ubi.pt/pag/brasil-andre-virtualdesbotado-das-webcams.html\#foot818\#foot818>. Acesso em: 07 dez. 2008.

CASALEGNO, Frederico. Sherry Turkle: fronteiras do real e do virtual. Revista FAMECOS, Porto Alegre, n. 11, dez. 1999. 
CASTELLS, Manuel. A sociedade em rede - a era da informação: economia, sociedade e cultura. São Paulo: Paz e Terra, 1999.

A galáxia da Internet. Rio de Janeiro: Jorge Zahar, 2003.

DELEUZE, Gilles; GUATTARI, Félix. O que é a filosofia. Rio de Janeiro: Editora 34, 1993.

LÉVY, Pierre. O que é o virtual? São Paulo: Editora 34, 1996.

MARÇAL, Maria Christianni C.; MELLO, Sérgio C.B.; CORRÊA, Maria Iraê S. Refletindo a tecnocultura e o culto ao corpo "Próprio"... Sobre a hibridização da técnica com o vivente. In: III ENECULT, 2007, Salvador. Anais do III Encontro de Estudos Multidisciplinares em Cultura. Salvador: UFBA, 2007.

MARÇAL, Maria Christianni C; MELLO, Sérgio C.B.; GUERRA, José Roberto Ferreira. Cultura e virtualidade real: um estudo sobre o consumo na Lan House. In: II ENECULT, 2006, Salvador. Anais do II Encontro de Estudos Multidisciplinares em Cultura. Salvador: UFBA, 2006.

MARTIN-BARBERO, Jesus. Dos meios às mediações: comunicação, cultura e hegemonia. 2. ed. Rio de Janeiro: Editora da UFRJ, 2003.

NÁSIO, Juan-Daid. Cinco lições sobre a teoria de Jacques Lacan. Rio de Janeiro: Zahar, 1993.

PLASTINO, Carlos A. O primado da afetividade: a crítica freudiana ao paradigma moderno. Rio de Janeiro: Relume-Dumará, 2001. p. 21-40.

RALEIRAS, Mônica. Recensão da obra "A vida no écrã. A identidade na era da internet", de Sherry Turkle. Sísifo - Revista de Ciências da Educação, n. 3, maio/ago. 2007. Disponível em: <http://sisifo.fpce.ul.pt>. Acesso em: dez. 2008.

SLATER, Don. Cultura do consumo e modernidade. São Paulo: Nobel, 2002.

TOURAINE, Alain. Crítica da modernidade. Petrópolis: Vozes, 1994.

VIRILIO, Paul.O espaço crítico. Rio de Janeiro: Editora 34, 1993.

. A máquina de visão. Tradução: Paulo Roberto Pires. Rio de Janeiro: José Olympio, 1994.

. A arte do motor. Tradução: Paulo Roberto Pires. São Paulo: Estação Liberdade, 1996.

. The Virilio reader. [s.1.]: James Der Derian/Blackwell Publishers, 1998.

ZIZEK, Slavoj. The plague of fantasies. London: Verso. 1997.

\section{NOTA}

1 Esse artigo é uma revisão de um paper publicado pelos autores no V Encontro de Estudos Multidisciplinares em Cultura da UFBA. 